\title{
Русский язык PRO
}

(некоторые последствия медиацентричности культуры)

\author{
Евгения Гурова \\ Наталья Ломыкина
}

\begin{abstract}
Рост интереса к вопросам грамотности сопровождается появлением на новых медийных площадках разных форм и форматов с ответами на вопросы по языкознанию. В статье рассматривается проблема отсутствия экспертной оценки на ресурсах, которым отдает предпочтение аудитория. Медиацентричность современной культуры оборачивается опасным разрушением традиций глубокого анализа. Смещение поиска языковой нормы в медиапространство должно заставить академическое сообщество пересмотреть подходы к просветительской работе и популяризации научного знания.

Ключевые слова: русский язык, медиацентричность культуры, экспертное мнение, медиакоммуникации вузов, популяризация науки.
\end{abstract}

DOI: 10.30547/mediaalmanah.5.2020.134140

(с) Гурова Евгения Константиновна кандидат филологических наук, доцент кафедры стилистики русского языка факультета журналистики МГУ имени М.В. Ломоносова (г. Москва, Россия), gromo-jeka@yandex.ru

(c) Ломыкина Наталья Юрьевна кандидат филологических наук, старший преподаватель кафедры стилистики русского языка факультета журналистики МГУ имени М.В. Ломоносова (г. Москва, Россия), ladylibra1410@gmail.com

\section{К постановке проблемы}

В последнее время можно отметить значительный рост интереса к русскому языку, вопросам грамотности, разным аспектам речетворческой деятельности. Спрос на "русский язык PRO» вызывает к жизни самые разные формы и форматы, так или иначе связанные с лингвистической проблематикой.

Издаются книги, популяризирующие русский язык как науку (Левонтина, 2010; Кронгауз, 2019; Милославский, 2015; Фуфаева, 2020), чрезвычайно востребованы справочно-информационные порталы (gramota. ru, gramma.ru, linguistic.ru, yazykoznanie.ru). Возникли целые движения, связанные со знанием правил русского языка, - с 2004 г. проводится ежегодное образовательное мероприятие "Тотальный диктант» под девизом «Писать грамотно - это модно!». В Сети легко найти подкасты, курсы лекций, тесты и другие интерактивные материалы, связанные с культурой письменной и устной речи, например научно-популярный подкаст о русском языке и лингвистике «Розенталь и Гильденстерн»1 или детский курс «Что мы знаем о языках и что языки знают о нас» ${ }^{2}$, не говоря уже о специализированных передачах и рубриках традиционных СМИ, таких как «Говорим по-русски» на «Эхе Москвы» или «Русский устный» на радио Sputnik. 
Эти инициативы поддерживаются и на государственном уровне: разработана Федеральная целевая программа «Русский язык»3, одной из важных задач которой является "расширение присутствия русского языка в сети Интернет».

И вот тут, в разгаре этого «расширения присутствия», академическое сообщество оказывается перед лицом одной из самых острых проблем современности: ни тиражи словарей и пособий, ни авторитет и статус ученых оказываются не в состоянии конкурировать в борьбе за внимание аудитории с популярными блогерами, которые претендуют на знание вопроса. Сравним ли 5000-й тираж книги профессора М. Кронгауза «Русский язык на грани нервного срыва», выдержавшей три переиздания, с 3,5 млн просмотров роликов Той Самой Училки (Татьяны Гартман) ${ }^{4}$, которая выступала «против ТВ», затем «против "Маяка"», а теперь - против всех, кто, по ее мнению, говорит и пишет неправильно? Причем ее аудитория продолжает неуклонно расти: лишь один раз разобрав ошибки, допущенные популярным журналистом Ю. Дудем, она заполучила несколько тысяч новых подписчиков.

Еженедельник «Аргументы и факты» собрал сведения о наиболее популярных сообществах, посвященных русскому языку5. На первом месте оказалась группа «ВКонтакте» «Я люблю русский язык» (в 2018 г. в ней было 1,36 млн подписчиков, а сейчас уже 1,6 млн). В сообществе «разбирают правила, приводят примеры распространенных ошибок, объясняют происхождение слов и так далее». Но кто взял на себя такую смелость - остается за кадром. В аккаунте группы в разделе «Информация» вместо имен и фамилий авторов дается ссылка на книги и карточки сообщества в интернет-магазине. То есть автора у этих публикаций нет, а читателей - больше полутора миллионов.

Если же мы посмотрим на то, насколько развита коммуникация серьезных научных организаций с интересующейся вопросами языка аудиторией, увидим интересные цифры. Посещаемость сайта Пушкинского дома (Института русской литературы Российской академии наукб) за август 2020 г. составила 60 тыс. визитов, а количество подписчиков в той же самой сети «ВКонтакте» - 539 человек7, чуть больше в Facebook - 2302 человека8. 59180 визитов у сайта Института русского языка имени В.В. Виноградова Российской академии наук 9 , а в соцсетях эта уважаемая научная организация не представлена вообще. Справочная служба русского языка с 2008 г. дает бесплатные телефонные (!) консультации по вопросам, связанным с нормами и правилами русского языка, но база данных Службы ${ }^{10}$, собранная за все эти 12 лет, насчитывает только 137000 записей, которые не доступны в открытых источниках.

\section{Специфика современной коммуникации и проблемы поиска языковой нормы}

Очевидно, что консервативное академическое сообщество не успевает реагировать на те необратимые масштабные изменения, которые произошли за последние двадцать лет в обществе и отечественной культуре вследствие цифровой революции. Мы стали свидетелями не просто технологических изменений и перестройки «медиаландшафта современного общества, в котором потребность аудитории в информации и коммуникации становится беспрецедентной» (Вартанова, 2012:8), трансформация оказалась гораздо глубже. Современный среднестатистический гражданин проводит в медиапространстве не менее 14 часов ${ }^{11}$ (для сравнения: в 2011 г. шесть часов ежедневно (Вартанова, 2011: 4)) и, соответственно, измеряет всю свою жизнь координатами медиа, что не могло не отразиться в языке.

В течение почти четырех столетий языковая картина мира определялась литературоцентричностью отечественной культуры, 
это сформировало устойчивые представления о норме и потребность ее поиска в авторитетных источниках, каковыми являлись не только словари, справочники и учебные пособия, но и тексты художественной литературы, изданные уважаемыми издательствами. Но уже в самом начале второго десятилетия XXI в. Г.Я. Солганик (2011: 260) с тревогой отмечал, что «происходит размывание литературной основы языка. Литературный язык "расплывается" в социальном пространстве. Масштабы этого процесса значительны, и существует опасность изменения качества литературного языка». В том же году И.В. Анненкова (2011: 13) уже фиксирует произошедшие изменения: «Современная отечественная культура утратила свой литературоцентризм и перешла в разряд медиацентричных культур, в которых язык средств массовой информации, коммуникации и пропаганды определяет культурспецифические черты того общества, в котором эти СМИ функционируют». Очевидные изменения оказались столь стремительными с точки зрения истории культуры, что ни специалисты, ни тем более носители языка не заметили, как поиск языковых норм сместился в новое коммуникативное пространство, а традиционно высокий уровень доверия аудитории к печатному слову естественным образом перешел от художественной литературы к медиа.

Одно из ключевых достижений технологической революции - появление в 2004 г. платформы Web 2.0 и принципиально иного, созданного пользователями контента12 - определило новые черты современной медиакоммуникации: она впервые стала взаимонаправленной. Именно двусторонность позволяет аудитории транслировать в Сеть четкий запрос на конкретную информацию. Но, увы, ответ на него далеко не всегда дается профессионалами. Что происходит с авторитетным и экспертным мнением теперь, когда мы живем в конвергентной, интерактивной, максимально визуализированной коммуникационной среде, о наступлении и вызовах которой социологи и теоретики медиакоммуникаций (Л. Белл, Ю. Хабермас, П. Бурдье и др.) говорили с середины 1960 гг. (Мультимедийная журналистика, 2017: 15)?

Хорошо, если поисковая система укажет на портал gramota.ru или выведет на просветителей-лингвистов - например, Ольгу Северскую, Марину Королеву, Ирину Анненкову или Татьяну Сурикову, многолетним сотрудничеством со СМИ завоевавших свою аудиторию. Но гораздо чаще поиск нормы приводит совсем не на авторитетные ресурсы. Доверчивый читатель может «нарваться» на примитивные объяснения инстаграм-страницы ru_lexicon (количество подписчиков - 107 тыс.) или на телеграмканал Учителя Русского (Teacherus, создатель и ведущий канала - чем он хуже Той Самой Училки?), советы которого по грамотности и культуре речи содержат нецензурную брань (и при этом - 36,5 тыс. подписчиков и индекс цитирования 133,79 (!), по данным Telegram Analytics, https://tgstat. ru/channel/@teacherus).

Даже умеющие верно сформулировать конкретный поисковый запрос профессиональные редакторы и корректоры, для которых русский язык - это действительно PRO, сталкиваясь с необходимостью подтвердить частный случай того или иного словоупотребления, написания или расстановки знаков препинания, подчас не находят в Сети актуальной, достоверной, экспертной информации по интересующему их поводу.

Кроме того, система поисковых запросов работает таким образом, что в ней подчас теряются, попадая на «второй экран», даже специализированные федеральные радиопрограммы, которые ведут лингвисты-эксперты, что уж говорить о других. Далеко не всегда по общим запросам о культуре речи поиск предлагает пользователю проекты и подкасты таких известных популяризаторов русского языка, как Ксения 
Туркова, Александр Пиперски, Гасан Гусейнов, и многих других лингвомедийныхличностей, получивших прекрасное профильное образование и обладающих глубокими знаниями предмета. Даже если их интернет-аудитория значительно шире, чем у специализированных программ, они все равно теряются в массовом потоке непрофессиональных рекомендаций и советов с броскими заголовками, «правильными» ключевыми словами и хештегами.

Медиасфера, вобравшая в себя все новые медиа и платформы, оказалась гораздо более широким пространством, чем можно было вообразить. В ней «свободно и бесконтрольно циркулирует огромное количество ложной и/или бесполезной информации, и мало кто уверенно ориентируется в этом потоке» ${ }^{13}$. Это применимо не только к языку, но и ко всем сферам человеческой жизни. Так, например, эпидемиологическая ситуация в мире в 2020 г. вызвала к жизни «пандемию публикаций о COVID-19», и лишь небольшая часть этих материалов содержит достоверные сведения и жизненно важные факты. А что в оставшейся, бо́льшей части? Непроверенная и откровенно ложная информация, появление которой провоцируется массовым интересом к проблеме. Как справедливо отмечают авторы статьи, размещенной на сайте habr.com., "такая дезинформация может быть опаснее явления, породившего угрозу»14.

Вдумаемся. Книга «Вальс гормонов» кубанского терапевта Натальи Зубаревой, благодаря популярности ее блога о женском здоровье, в 2018 г. стала, по данным Forbes 15 , самой продаваемой нон-фикшн книгой по эндокринологии. Композитор и певец Юрий Лоза на своем канале за две минуты с легкостью доказал, что Земля на самом деле плоская (и это не единственная область человеческой деятельности, в которой он оказался компетентен) ${ }^{16}$; национал-социалистическая партия Германии благодаря «просвещающим» роликам
YouTube постепенно превращается в либеральную17. То ли еще будет?

Медиацентричность в итоге обернулась опасным размыванием поля экспертного мнения и глубокого анализа. И такой востребованный русский язык в новой медиареальности оказывается совсем не PRO. Понимая всю масштабность возникшей проблемы, профессор И.В. Анненкова в одном из своих интервью с горечью восклицает: «Где ученые-гуманитарии на страницах наших главных газет, на порталах главных изданий - где они? Где дмитрии сергеевичи лихачевы?»18. К сожалению, пока мы имеем только парадоксальное противостояние: в лучшем случае еженедельное появление профессора на «Маяке» 19 и непрерывная кампания «Училки против "Маяка"».

\section{Высшая школа против дилетантства}

На первый взгляд, представляется совершенно очевидным, что существующие гигантские пробелы в знании языка должны заполнить в новой медиасреде реальными знаниями, советами и рекомендациями лингвисты-профессионалы: профессора, доценты, научные сотрудники вузов и исследовательских институтов. Но не все так просто.

Принятое в академической науке строгое цитирование и обязательная опора на первоисточник, научная традиция диахронического изучения любой проблемы, с одной стороны, придают значительный вес высказываниям и мнениям ученых, а сдругой - делают любое обсуждение актуальных проблем закрытым для широкой общественности. А официальные требования к работе исследователей, привязка к индексу цитирования, необходимость соблюдения и защиты авторских прав и другие условия существенно осложняют выход экспертов в открытое медийное пространство. Ученые продолжают фиксировать и исследовать все изменения современного языка и пополнять научный корпус текстов, обогащая библиотечные фонды и лингвистическую 
науку в ее традиционных формах. И тут мы сталкиваемся с «эффектом фонаря»: носители языка давно уже за ответами на любые интересующие их вопросы идут не в библиотеки, а туда, «где светлее», - в Интернет, то есть как раз туда, где размещать и популяризировать свои достижения ученым по разным причинам даже не приходит в голову.

Представляется, что в условиях медиацентричности культуры высшие учебные заведения не могут ограничиваться только реализацией образовательных программ, а должны брать на себя в том числе решение просветительских задач и популяризацию научного знания.

Московский университет всегда уделял огромное внимание просвещению: десятилетиями работал открытый Лекторий, который могли посещать все желающие, независимо от пола, возраста и уровня образования; профессора и выпускники издавали периодику, посвященную разным областям науки, прекрасно понимая, какую роль играют альманахи и журналы в распространении научных знаний 20 . И сейчас руководство ведущего вуза страны следует этим традициям, продолжая популяризаторскую деятельность: организует межфакультетские курсы для студентов, лекции на открытых площадках, приветствует отдельные выступления преподавателей и научных сотрудников в традиционных СМИ. Но колоссальные возможности новых медиа практически не используются. А ведь новые каналы коммуникации позволяют обеспечить широкий охват аудитории, не сопоставимый с лекцией в традиционном формате.

Нельзя сказать, что высшая школа не освоила новые возможности: вузы имеют свои сайты, размещают информацию в различных социальных сетях, но эта деятельность осуществляется пока только в рамках формирования событийной повестки и обновления рабочих материалов. Для решения административных и организационных вопросов на уровнях «деканат - учебная часть - студент», «приемная комиссия - абитуриент» и даже «преподаватель - группа» возможности новых каналов коммуникации давно используются, но за пределы учебного процесса такая практика не выходит.

Просветительские задачи высшей школы не должны ограничиваться вертикалью «вуз - студенты», необходимо расширять коммуникативное поле по горизонтали («вуз - граждане»), по-новому осваиваясь в медиапространстве. Прекрасно, когда просветительскую миссию берут на себя федеральные СМИ и появляются такие масштабные проекты, как Academia на телеканале «Культура», где записываются, выходят в эфир и появляются на сайте лекции академиков и ученых с мировым именем в разных областях науки, в том числе и в языкознании ${ }^{21}$, но законы новой инфокоммуникационной среды требуют, чтобы эту работу выполняли и сами вузы. Сейчас, когда пандемия COVID-19 вынудила высшую школу оперативно перейти на новые формы обучения, самое время не только использовать достижения цифровой революции для внутренних целей, но и осваивать новые площадки для расширения влияния на умы сограждан.

Другим ключевым направлением просветительской работы вуза видится развитие у студентов критического мышления, умения ориентироваться в океане самой разной информации и способности не только верифицировать полученные данные, но и быстро и точно определять авторитетность источника и степень достоверности сведений. Но это тема отдельного серьезного разговора. 


\section{Примечания}

1 Розенталь и Гильденстерн. Режим доступа: https://meduza.io/podcasts/rozental-igildenstern (дата обращения: 10.09.2020).

2 Детский курс о лингвистике. 10 лекций. Режим доступа: https://arzamas.academy/ radio/announcements/linguistics-3 (дата обращения: 10.09.2020).

3 Программа опубликована на официальном сайте Правительства Российской Федерации. 2014. Дек., 20. Режим доступа: http://rs.gov.ru/uploads/document/file/13/ fcp2016.pdf (дата обращения: 17.09.2020).

4 Сайт Той Самой Училки. Режим доступа: https://uchilkaonline.ru/ (дата обращения: 17.09.2020).

5 Власенко А., Алексеева Л. Русский онлайн. Самые интересные блоги о грамотности // Аргументы и факты. 2018. Март, 22. Режим доступа: https:/aif.ru/society/ education/russkiy_onlayn_samye_interesnye_blogi_o_gramotnosti (дата обращения: 24.09.2020).

6 Официальный сайт Института русской литературы (Пушкинского дома) РАН. Режим доступа: http://pushkinskijdom.ru/ (дата обращения: 06.10.2020).

7 Страница официальной группы Института русской литературы (Пушкинского дома) РАН в сети «ВКонтакте». Режим доступа: https://vk.com/pushkinskijdom (дата обращения: 06.10.2020).

8 Страница группы Института русской литературы (Пушкинского дома) РАН в сети Facebook. Режим доступа: https://www.facebook.com/pushkinblog (дата обращения: 06.10.2020).

9 Официальный сайт Института русского языка имени В.В. Виноградова РАН. Режим доступа: http://www.ruslang.ru/ (дата обращения: 06.10.2020).

10 Страница Справочной службы русского языка на официальном сайте Института русского языка имени В.В. Виноградова РАН. Режим доступа: http://www.ruslang. ru/sprav (дата обращения: 06.10.2020).

11 МедиаТренды. 2019. № 6 (69). С. 2.

12 Мирошниченко А. Взрыв медиа: как жить, когда 2 миллиарда читателей превращаются в писателей // Forbes. 2011. Окт., 14. Режим доступа: https://www.forbes.ru/ ekonomika-column/rynki/75118-vzryv-media-kak-zhit-kogda-2-milliarda-chitateleiprevrashchayutsya-v-p (дата обращения: 24.09.2020).

13 Грант Дж. Не верю! Как увидеть правду в море дезинформации / пер. с англ. М.: Альпина Паблишер, 2017. С. 12.

14 «Пандемия» научных публикаций о COVID-19. 2020. Март, 22. Режим доступа: https://habr.com/ru/post/493512/ (дата обращения: 18.09.2020).

15 Ломыкина Н. От блогеров к черным магам. Самый продаваемый нон-фикшн 2018 // Forbeslife. 2018. Дек., 29. Режим доступа: https://www.forbes.ru/forbeslifephotogallery/371089-ot-blogerov-k-chernym-magam-samyy-prodavaemyy-nonfikshn-2018 (дата обращения: 30.09.2020).

16 Глыба К. «Не все так кругло»: Юрий Лоза за две минуты доказал, что Земля плоская // Комсомольская правда. 2020, 17 сентября. Режим доступа: https://www. kp.ru/daily/217183/4289282/ (дата обращения: 18.09.2020).

${ }_{17}$ Scott S. YouTube's algorithm is spreading a series of unfortunate far-right events. Peжим доступа: https://medium.com/@samuelscott/youtubes-algorithm-is-spreadinga-series-of-unfortunate-far-right-events-cc6652e76е88 (дата обращения:30.09.2020).

18 Янгляева М. О метасмыслах в языке // Мужская работа. 2016. № 55. Март, 5. Режим доступа: http://www.menswork.ru (дата обращения: 10.10.2020). 
19 Сергей Стиллавин и его друзья. Ирина Васильевна Анненкова, профессор кафедры стилистики русского языка факультета журналистики МГУ, доктор филологических наук. Режим доступа: https://radiomayak.ru/persons/person/id/24302l/ (дата обращения: 17.09.2020).

20 Журналисты, писатели, издатели - питомцы и профессора Московского университета (1755-1917). Словарь / под общ. ред. Т.Ф. Пирожковой; сост.: И.В. Петровицкая, Н.В. Фролова. М.: ИКАР, 2014.

${ }^{21}$ См., напр., лекцию Андрея Зализняка «Русский устный» о трудностях русского ударения. Режим доступа: https://tvkultura.ru/video/show/brand_id/20898/episode_ id/973669/video_id/983735/viewtype/ (дата обращения: 30.09.2020). Или лекцию Светланы Тер-Минасовой «На зеркало неча пенять... Язык - зеркало культуры» о современной жизни, отраженной в зеркале языка. Режим доступа: https://tvkultura. ru/video/show/brand_id/20898/episode_id/691681/ (дата обращения: 30.09.2020).

\section{Библиография}

Анненкова И.В. Медиадискурс XXI века: лингвофилософский аспект языка СМИ. М.:

Фак. журн. МГУ; Изд-во Моск. ун-та, 2011.

Вартанова Е.Л. О необходимости модернизации концепций журналистики и СМИ // Вестн. Моск. ун-та. Сер. 10: Журналистика. 2012. № 1. С. 7-26.

Вартанова Е.Л. Язык российских СМИ как индикатор социальных перемен // Язык СМИ и политика. М.: МедиаМир, 2011. С. 3-7.

Кронгауз М.А. Русский язык на грани нервного срыва. 4-е изд., испр. и доп. М.: АСТ:

Corpus, 2019.

Левонтина И.Б. Русский со словарем. М.: Азбуковник, 2010.

Милославский И.Г. Русский язык на каждый день и навсегда: моногр. М.: КД «Университет», 2015.

Мультимедийная журналистика: учебник для вузов / под общ. ред. А.Г. Качкаевой, С.А. Шомовой. М.: ИД ГУ ВШЭ, 2017.

Солганик Г.Я. Язык политики, язык СМИ (газеты) и литературный язык // Язык СМИ и политика. М.: МедиаМир, 2011. С. 245-261.

Фуфаева И. Как называются женщины. Феминитивы: история, устройство, конкуренция. М.: Corpus, 2020. 